\title{
Author Correction: Chlorine activated stacking fault removal mechanism in thin film CdTe solar cells: the missing piece
}

\author{
Peter Hatton (1), Michael J. Watts, Ali Abbas, John M. Walls, Roger Smith (1) \& Pooja Goddard (1)
}

Correction to: Nature Communications https://doi.org/10.1038/s41467-021-25063-y, published online 23 August 2021.

The original version of this Article omitted the Acknowledgements: EPSRC Studentship 1801035; EPSRC Grant Nos. EP/P020232/1, EP/L000202, EP/R029431, EP/P020194.

This has been corrected in both the PDF and HTML versions of the Article.

Published online: 14 January 2022

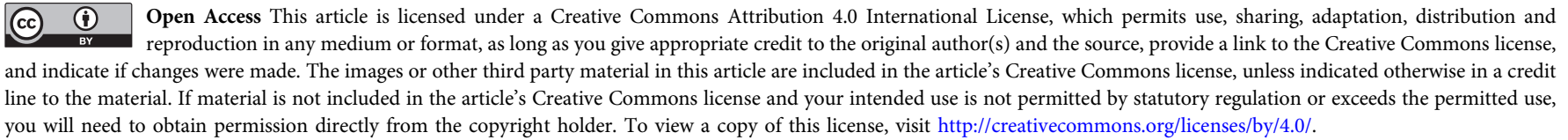

you will need to obtain permission directly from the copyright holder. To view a copy of this license, visit http://creativecommons.org/licenses/by/4.0/.

(c) The Author(s) 2022 